\section{BMJ Paediatrics Open}

\title{
Parental perceptions of the impact of neonatal unit visitation policies during COVID-19 pandemic
}

Hemananda Muniraman (D) , ,2,3 Mahmoud Ali, ${ }^{4}$ Paul Cawley (D) , Jessica Hillyer, ${ }^{4}$ Adam Heathcote, ${ }^{6}$ Vennila Ponnusamy, ${ }^{7}$ Zoe Coleman, ${ }^{2}$ Kendall Hammonds, ${ }^{8}$ Chandni Raiyani, ${ }^{8}$ Eleanor Gait-Carr, ${ }^{9}$ Sarah Myers, ${ }^{9}$ Katie Hunt, ${ }^{5}$ Vinayak Govande, ${ }^{4}$ Anoo Jain, ${ }^{5}$ Reese Clark, ${ }^{10}$ Cora Doherty, ${ }^{9}$ Venkata Raju, ${ }^{4}$ Paul Clarke (D) ${ }^{6,11}$

\section{ABSTRACT}

Objectives To ascertain parental perceptions of the impact of restricted visiting policies to neonatal intensive care units during the current COVID-19 pandemic.

Design Cross-sectional survey of parents impacted by visitation policies.

Setting Six tertiary level neonatal units, four from the UK and two from the USA, participated in the study.

Participants Parents and families of infants hospitalised in the participating centres between 1 May 2020 and 21 August 2020.

Methods Online-based and/or paper-based survey, querying the visitation policies and their impact on parents ability to visit, care for and bond with their infants.

Results A total of 231 responses were received. Visitation limited to a single visitor with no restrictions on duration was the most frequently reported policy; $140 / 217$ (63\%). Visitation policies were perceived as being restrictive by $62 \%(138 / 219)$ of the respondents with $37 \%$ (80/216) reporting being able to visit less often than desired, $41 \%(78 / 191)$ reporting being unable to bond enough and $27 \%(51 / 191)$ reporting not being able to participate in their baby's daily care. Mild to severe impact on breast feeding was reported by $36 \%$ (75/209) of respondents. Stricter policies had a higher impact on families and were significantly associated with a lack of bonding time, inability to participate in care and an adverse impact on breast feeding.

Conclusions Visitation policies during the COVID-19 pandemic varied between centres and over time with stricter restrictions implemented earlier on in the pandemic. Parents reported significant impacts on their ability to visit, care for and bond with their infants with perceived severity of impact worse with stricter restrictions.

\section{employer(s)) 2020. Re-use} permitted under CC BY-NC. No commercial re-use. See rights and permissions. Published by BMJ.

For numbered affiliations see end of article.

Correspondence to Dr Hemananda Muniraman; hemu_muniraman@mednax. com

\section{What is known about the subject?}

The current COVID-19 pandemic has led to widespread visitation restrictions for parents and families in neonatal intensive care units.

- The impact of these restrictions on parental ability to visit and care for their infants is unknown.

\section{What this study adds?}

Restriction policies varied between centres and over time, with stricter restrictions implemented early in the pandemic.

- Parents reported significant impact on their ability to visit and care for their infants, and this impact was more severe with stricter visitation policies.

been shown to improve safety and quality of care and have wide-ranging benefits including improved weight gain, higher rates of breast feeding, decreased length of stay, decreased nosocomial infection, decreased parental anxiety and stress, improved discharge readiness and parental satisfaction rates. ${ }^{5-7}$ Parent-infant interaction including skinto-skin contact and kangaroo care supports strong development of physical, emotional and psychological bonding and improves neurodevelopmental outcomes. ${ }^{8} 9$ For effective FCC, FIC and patient-infant bonding, parental presence and strong commitment from both parents and healthcare providers are essential.

In little over 8 months, the current COVID-19 pandemic caused by the severe acute respiratory syndrome coronavirus-2 (SARS-CoV-2) virus has infected over 40 million people and contributed to 1.1 million deaths worldwide. ${ }^{10}$ However, there are only a few case reports of vertical 
transmission in neonates with SARS-CoV-2 published in the literature. ${ }^{11-14}$ The American Academy of Pediatrics (AAP) neonatal-perinatal COVID-19 registry update of 3 October 2020 reported that, among 3722 mother/infant dyads and 3359 COVID-19 positive mothers, only 52 $(1.6 \%)$ of 3198 infants tested positive for SARS-CoV-2. ${ }^{15}$

Social distancing and wearing face masks/coverings have been shown to mitigate the spread of viral transmission. Healthcare institutions have also implemented severe visitation restrictions to control SARS-CoV-2 spread and protect the health of patients, providers and staff. The restrictions vary widely depending on local infection rates, availability of personal protective equipment and the structure and layout of the NICU. ${ }^{16} 17$ The impact of any of the restrictions on parental ability to be present and care for their infants is not well defined. Our aim was to ascertain parental perceptions of the impact of visitation restrictions during the COVID-19 pandemic on their ability to visit, care for and bond with their infants.

\section{METHODS}

We designed an 18-item questionnaire to survey parents/ guardians of infants hospitalised for prospective participating neonatal units during the COVID-19 pandemic, to assess perceptions of visitation restrictions and their impact. The anonymous questionnaire included both closed and open ended questions and free-text comment sections for respondents to provide additional responses if applicable (online supplemental file 1).

\section{Patient involvement}

Patients or the public were not involved in the design or conduct of the study, but were involved in its peer review and advising on the dissemination of our research.

\section{Participating centres and participants}

We used a pragmatic approach to recruit centres and parents to participate in the survey by disseminating an open invitation over social media platforms including Twitter, neonatal forums, via email and WhatsApp groups. Centres determined their own preferred methods for publicising the study locally to parents and distributing the study information. These included poster notices in the units, social media/communication platforms for parents, and direct mailing of the survey to parents whose infants had recently been discharged from the hospital. All centres conducted a cross-sectional survey of parents of infants hospitalised at the start of the study, followed by prospective survey of parents of infants admitted thereafter during the study period. Additionally three centres mailed the survey questionnaire to parents whose infants had been recently discharged. Paper and/ or online questionnaire responses were recorded via SurveyMonkey (Palo Alto, California, USA) during the study period between 1 May 2020 and 21 August 2020. An information sheet provided along with the survey/online questionnaire summarised the purpose and objectives of the study and explained the rights of participants. Participants were required to document their prior agreement to participation in the survey by first answering a consent question. A second survey was sent to site investigators to enquire about the timing and nature of visitation restriction policies and any changes over time.

\section{Statistical analysis}

Respondents' characteristics and responses were described with descriptive statistics using frequencies and percentages to report categorical variables. Means and SDs (or medians and ranges where appropriate) were used to describe continuous variables. Perceptions of impact were compared between countries, centres and across different restriction policies: (1) one visitor at cotside for limited duration; (2) one visitor with no restriction on duration of visit and (3) two visitors for limited duration. Associations in bivariate comparisons were examined using $\chi^{2}$ or Fisher's exact tests as appropriate. A Wilcoxon rank-sum test was performed to assess the difference in ordinal variables between two groups. A Kruskal-Wallis test was performed to assess the difference in ordinal variables between three or more groups. Statistical significance was set at $p<0.05$. To control for multiple comparisons, the false discovery rate (FDR) correction was applied to all $p$ values, assuming a $\operatorname{FDR}\left(q^{*}\right)$ equal to $0.05{ }^{17}{ }^{18}$ All statistical analyses were performed in SAS V.9.4 (SAS Institute).

\section{RESULTS}

Six tertiary level NICUs participated, four from the UK and two from the USA. Two hundred and thirty-one responses were received, of which 7 were excluded (1 lacking consent signature, 2 from non-participating sites, 4 for incomplete information on visitation policies). A total of 224 responses were included for final analysis: USA: $\mathrm{n}=131$ (58\%), UK: $\mathrm{n}=93$ (42\%). Breakdown of responses by centre was: Baylor Scott \& White McLane Children's Medical Center, Texas, USA: 80, St Joseph's Hospital and Medical Center, Phoenix, USA: 51, St Michael's Hospital (SMH), Bristol, UK: 31, Ashford and St Peter's Hospital, Chertsey, UK: 27, Norwich and Norfolk University Hospital (NNUH), Norwich, UK: 25 and University Hospital of Wales, Cardiff, UK: 10.

Of respondents, $153(70 \%)$ were mothers, $58(27 \%)$ fathers and 5 (2\%) were grandparents. Remaining $2(1 \%)$ respondents were a sibling and a guardian. Mean (SD) age of respondents was $32(7)$ years. The birth gestation of index infants was reported as being term ( $\geq 37$ weeks) by $71(34 \%)$ respondents, late preterm $\left(34-36^{+6}\right.$ weeks $)$ by $36(17 \%)$, moderately preterm $\left(28-33^{+6}\right.$ weeks $)$ by 61 $(30 \%)$ and extremely preterm $(<28$ weeks $)$ by $39(19 \%)$ respondents. Length of hospitalisation at the time of survey completion was reported as $<1$ week by $100(45 \%)$, between 1 and 4 weeks by $70(32 \%)$ and $>4$ weeks by 50 (23\%) respondents. 

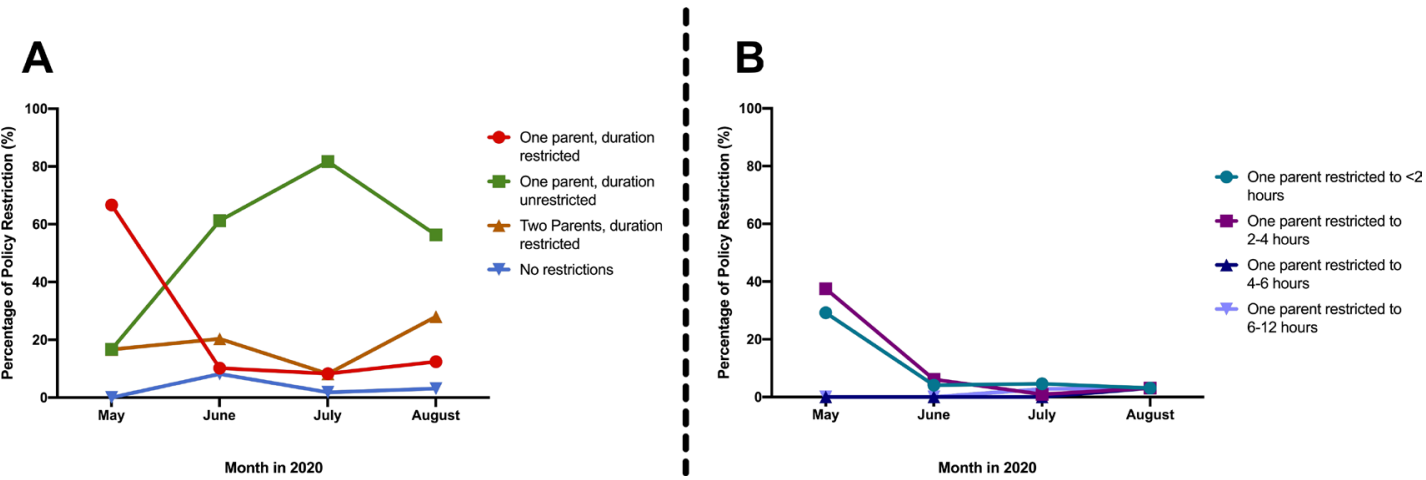

Figure 1 Visitation policies over time during study period. (A) Restriction by visitor number and restricted versus unrestricted duration. (B) Breakdown of visitation policy by length of restricted duration.

\section{Restriction policies}

The most common visitation policy overall limited visiting to just one person at a time, although for an unlimited period, reported by $140(63 \%)$ respondents, followed by allowing two visitors for a limited duration, reported by $42(19 \%)$ respondents. Policies changed significantly over time: during May 2020, the most common policy was restriction to one visitor with restricted duration. During June, July and August 2020, the most common policy was one visitor at a time for an unlimited duration (figure 1, table 1).

Of the respondents, $122(56 \%)$ reported that the restrictions did not affect their ability to visit, whereas $80(37 \%)$ reported visiting less often and $14(7 \%)$ more often. Regarding the wider family's ability to visit, 84 $(40 \%)$ reported their partner had visited less often, while $98(45 \%)$ and $115(54 \%)$ reported concerns that siblings and grandparents were not allowed to visit, respectively.

Concerns about the visitation policies were reported by $94(50 \%)$ respondents: $78(41 \%)$ respondents felt unable to bond adequately with their infant and 51 (27\%) reported being unable to participate in their baby's daily cares. A mild impact on breast feeding was reported by 50 (24\%) respondents while a severe impact was reported by $25(12 \%)$ respondents. Video/audio recordings or streaming were perceived as unhelpful by $36(17 \%)$ respondents, many of whom expressed concerns that they received insufficient information and updates about their infants.

Majority of respondents, $176(83 \%)$ reported a requirement to wear a face mask when visiting the NICU: 95 $(45 \%)$ of respondents reported that wearing face masks was appropriate, while $73(34 \%)$ reported that wearing a face mask affected bonding and $46(21 \%)$ reported that the wearing of masks by staff made their interactions with staff less personal.

\section{Comparison of different restriction policies}

There was no difference in respondents' reported ability to visit with the different restriction categories $(\mathrm{p}=0.18)$ (table 2). A policy of one visitor restricted to limited duration was associated with a higher proportion of concerns of lack of bonding, inability to participate in care, obtain updates and bring supplies, followed by two visitors with a restriction on duration of visit. A policy of one visitor and unrestricted visit duration was associated with a lower proportion of concerns $(\mathrm{p} \leq 0.02)$ (table 2 and figure 2$)$. Respondents subject to policy restrictions of one parent for a limited time were more likely to perceive a mild or severe impact compared with those facing less austere restrictions $(p=0.02)$ (table 2 and figure 2 ).

Restriction policy and month of response varied among the centres, with the majority of responses from the UK in May and June 2020, and the US centres in July and August 2020 (table 3). Respondents from centres with more restrictive policies in May and June 2020 reported higher rates of insufficient bonding, higher rates of being unable to participate in their infants' care and more mild and severe impacts on breast feeding $(\mathrm{p}=0.01)$ (table 4). The centre with the least restrictive policy on parental visiting (SMH, Bristol, UK) reported the lowest rates of both inability to participate and insufficient bonding $(p=0.01)$. The centre with the most austere restrictions (NNUH, UK) had the greatest associated rates

Table 1 NICU restriction policy compared by months of responses

\begin{tabular}{|c|c|c|c|c|c|}
\hline \multirow[b]{2}{*}{ Restriction policy } & \multicolumn{4}{|l|}{ Month } & \multirow[b]{2}{*}{ P value } \\
\hline & May & June & July & August & \\
\hline One parent at cotside with restricted visit duration $(n=35)$ & $17(48)$ & $5(14)$ & $9(26)$ & $4(11)$ & $<0.01$ \\
\hline One parent at cotside with unrestricted duration $(n=140)$ & $4(3)$ & $30(21)$ & $88(63)$ & $18(13)$ & \\
\hline Two family members at cotside with restricted visit duration $(n=42)$ & $5(12)$ & $14(33)$ & $13(31)$ & $10(24)$ & \\
\hline
\end{tabular}

Data are $\mathrm{n}(\%)$. A chi-square $\mathrm{c}^{2}$ test was performed to assess the association between NICU restriction and month of completion.

$\mathrm{NICU}$, neonatal intensive care unit. 
Table 2 Impact of restriction policies

\begin{tabular}{|c|c|c|c|c|}
\hline & $\begin{array}{l}\text { One parent at cotside with } \\
\text { restricted visit duration } \\
(n=35)\end{array}$ & $\begin{array}{l}\text { Two family members at } \\
\text { cotside with restricted visit } \\
\text { duration }(n=41)\end{array}$ & $\begin{array}{l}\text { One parent at cotside } \\
\text { with unrestricted } \\
\text { duration }(n=136)\end{array}$ & $P$ value* \\
\hline Respondent visit less often & $20 / 35(57)$ & $16 / 41(39)$ & $44 / 134(33)$ & $0.18 \dagger$ \\
\hline Partner visit less often & $18 / 33(55)$ & $12 / 41(29)$ & $54 / 133(41)$ & 0.17( \\
\hline Not enough bonding & 23/31 (74) & $16 / 37(43)$ & $39 / 116(34)$ & $<0.01$ \\
\hline Unable to participate in cares & $17 / 31(55)$ & 13/37 (35) & $21 / 116(18)$ & $<0.01$ \\
\hline Unable to receive updates & $14 / 31(45)$ & $9 / 37(24)$ & $14 / 116(12)$ & $<0.01$ \\
\hline $\begin{array}{l}\text { Unable to bring milk and } \\
\text { supplies }\end{array}$ & $8 / 31(26)$ & $3 / 37(8)$ & $7 / 116(6)$ & $0.02 \dagger$ \\
\hline Breast feeding & & & & $0.02 \ddagger$ \\
\hline No impact & $7 / 23(30)$ & 18/33 (55) & $66 / 110(60)$ & \\
\hline Mild impact & $8 / 23(35)$ & $7 / 33(21)$ & 35/110 (32) & \\
\hline Severe impact & $8 / 23(35)$ & $8 / 33(24)$ & $9 / 110(8)$ & \\
\hline
\end{tabular}

Data are $\mathrm{n}(\%)$.

${ }^{*}$ Analysed by chi-square test unless specified.

†Fisher's exact test.

$\ddagger$ Kruskal-Wallis test

of mild and severe adverse impacts on breast feeding reported $(p=0.01)$ (table 4$)$. There were no differences in responses based on countries reported for visiting, bonding or caring for infants $(\mathrm{p}>0.05)$.

\section{Comments from parents}

Comments from parents regarding visitation policies further demonstrated their impact, especially at the beginning of the pandemic when restrictions were most severe, and with extremely ill infants during end of life scenarios. One mother wrote:

I will remember this for the rest of my life. I will also remember the kindness of the staff but at 18 hours old I was told my baby might die and I had to beg to see him because I had already had my 2 hours. How is that ok???

Several comments related the impact of visitation polices on parental mental health:

Felt like my baby was not mine and I was asking permission from the nurses. Also has made me feel resentful towards [my] husband as all the emotional burden of a child in NICU fell upon myself;

The visiting times force a choice between cuddles and learning how to tube feed etc. Consequently this has left me feeling like I don't take good care of my baby. Not acceptable for a postnatal women. I would imagine PND [post-natal depression] will be very high in this epidemic.

The comments in July and August 2020 predominantly related concerns about being unable to spend time together as family:
I have found the visiting restrictions very tough and would love for nothing more than myself and my partner to be able to see our child together. It has been an extremely tough few weeks emotionally and I wish we could support each other in NICU together and be prepared for discharge.

Comments from respondents are summarised in full in online supplemental file 2 .

\section{DISCUSSION}

We report the results of a bi-national survey of parents affected by neonatal unit visitation policies during the current COVID-19 pandemic. This pandemic has led to widespread restrictions on family visiting to the hospital, especially in intensive care units where the most critical patients are cared for. ${ }^{17}$ NICUs present a unique setting where infants often stay for weeks to months and parents play a vital role in their care. There has been a paradigm shift in the parental role in the neonatal unit; parents are no longer considered 'just visitors' but rather an integral and essential part of care provision. ${ }^{1-5}$ However, the pandemic and resultant visitation restrictions have severely disrupted the parental presence and their ability to facilitate and augment care in the NICU. The short-term and long-term effects of these restrictions are unknown, but may be significant. ${ }^{19}$

While we found that the majority of parents understood the need for revised visitation policies, they reported significant concerns about their consequent ability to visit, care for, and bond with their infants. The visitation restrictions were implemented between midMarch and early April 2020 in the USA and UK during the early stages of the pandemic. Our study shows that 
A.
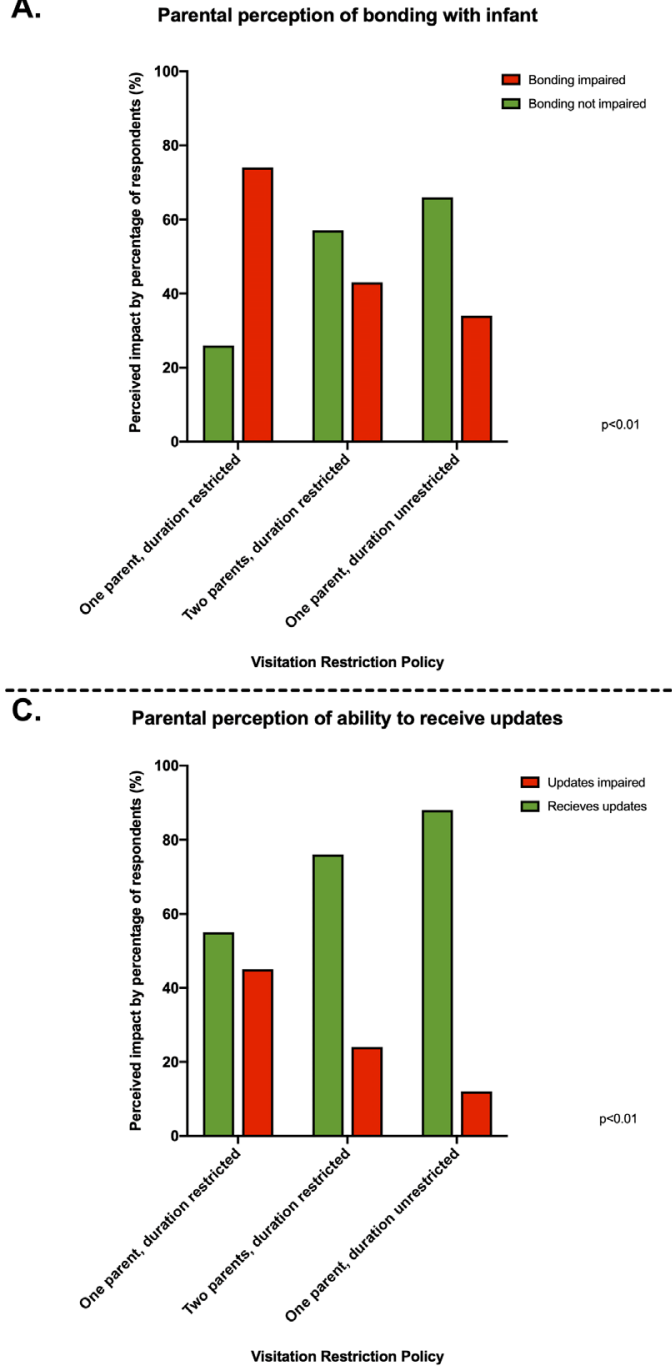

B.

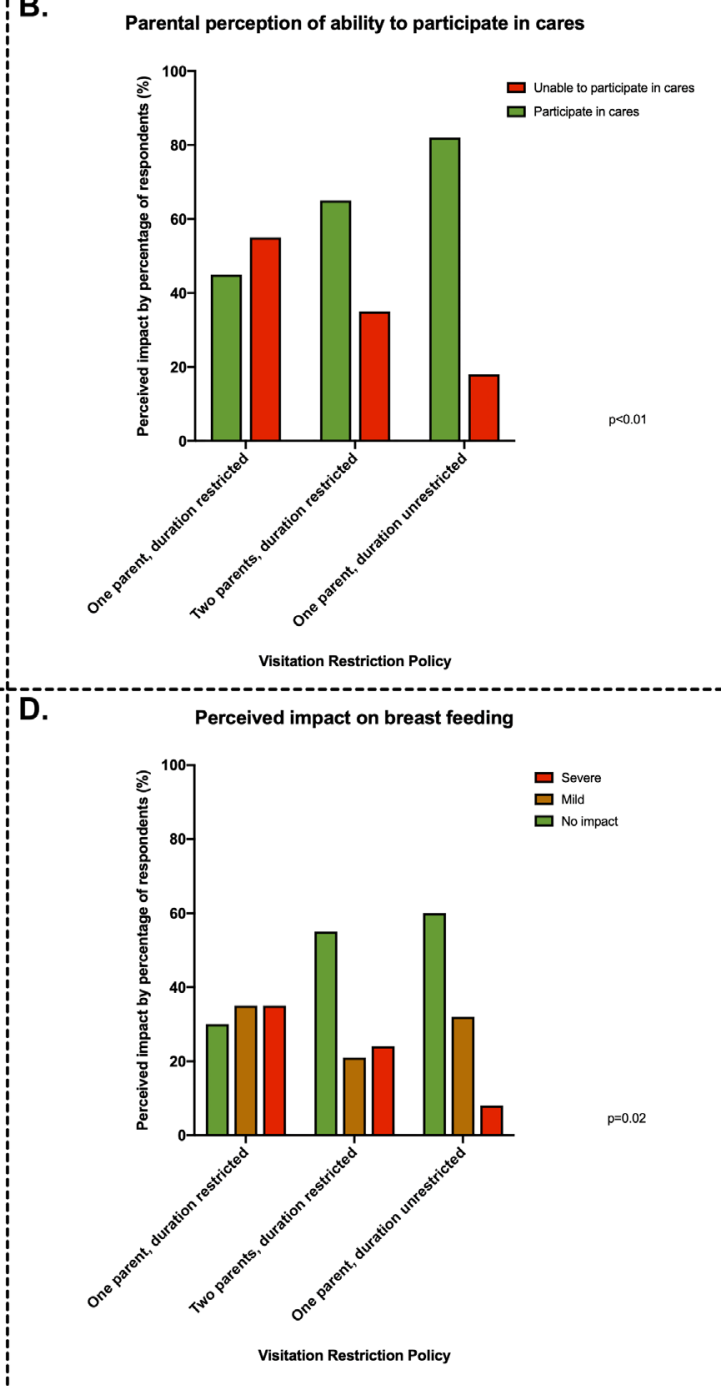

Figure 2 Parental perception of impact of restriction policies.

parents have been significantly impacted since this time, especially with being denied the opportunity to spend time with their critically ill infants and particularly during end of life situations. The initial guidance of the AAP on management of infants born to suspected and confirmed COVID-19 positive mothers during this period recommended temporary separation of the infant pending testing of both infant and mother. ${ }^{20}$ By June and August 2020, with mounting evidence of the low risk of vertical transmission, very few case reports of neonates being affected, and better availability of personal protection equipment, modified restrictions permitted one or both parents to spend more time with their babies. Our data suggest that this resulted in a less severe impact, with fewer major concerns about being unable to spend sufficient time together as a family. The AAP has since revised its guidance to recommend rooming in for parents with mild to moderate symptoms, with appropriate isolation precautions. ${ }^{21}$

Within the UK, early national guidance in March 2020 relating to NICU visitation policies was limited; reflecting the scarcity of evidence. However, separation of an otherwise well infant from a SARS-CoV-2 positive mother was not advocated and breast feeding was not discouraged providing that hygiene precautions were adhered to. ${ }^{22} \mathrm{By}$ April and May 2020, more comprehensive guidance was jointly issued by the UK Royal College of Paediatrics and Child Health (RCPCH), British Association of Perinatal Medicine and Bliss baby charity; they strongly advocated for the role of parents as part of the infant's therapeutic team and not as mere visitors, and as such stressed that 'parental restrictions should be exercised only when absolutely necessary, as a temporary and proportionate response to a peak in viral transmission'. ${ }^{23-25}$ Restricted visiting on time of day was discouraged and, where possible, units were advised to allow parents to be present together. ${ }^{23-25}$ In June 2020, RCPCH medical guidance advised a nuanced response: that parent and baby form one family 'bubble', and that cotside face coverings would be unlikely to offer significant additional protection if sufficient spacing was maintained from other staff, parents and visitors. ${ }^{23}$ 
Table 3 Visitation policies and date of implementation dates among participating centres

\begin{tabular}{|c|c|c|}
\hline Centres & Visitation policy/policies & Implementation date \\
\hline $\begin{array}{l}\text { Norfolk and Norwich University } \\
\text { Hospital, Norfolk, UK }\end{array}$ & $\begin{array}{l}\text { 1. Only one parent allowed at a time to visit for a } \\
\text { limited duration (for maximum } 2 \text { hours/day) } \\
\text { 2. Only one parent allowed at a time to visit for a } \\
\text { limited duration (for a 4-hour period per day) } \\
\text { 3. Both parents allowed to visit together at a time, } \\
\text { but for a limited duration (3hours/day) }\end{array}$ & $\begin{array}{l}\text { 1. } 27 \text { March } 2020 \text { to } 5 \text { May } 2020 \\
\text { 2. } 6 \text { May } 2020 \text { to } 25 \text { May } 2020 \\
\text { 3. } 26 \text { May } 2020 \text { to September } 2020 \text { (to } \\
\text { date) }\end{array}$ \\
\hline St Michael's Hospital, Bristol, UK & $\begin{array}{l}\text { Two parents allowed at cotside for infants in } \\
\text { intensive care areas. One parent (either parent) } \\
\text { at cotside for infants in high dependency/special } \\
\text { care areas. No time restrictions on visiting in any } \\
\text { dependency areas }\end{array}$ & $\begin{array}{l}8 \text { April } 2020 \text { to September } 2020 \text { (to } \\
\text { date) }\end{array}$ \\
\hline $\begin{array}{l}\text { St Joseph's Hospital and Medical } \\
\text { Center, Arizona, USA }\end{array}$ & $\begin{array}{l}\text { 1. Two family members allowed at a time for } \\
\text { unlimited duration } \\
\text { 2. Only one parent allowed at a time with no } \\
\text { restriction on duration of visit }\end{array}$ & $\begin{array}{l}\text { 1. } 15 \text { March } 2020 \\
\text { 2. } 23 \text { March } 2020 \text { to September } 2020 \\
\text { (to date) }\end{array}$ \\
\hline $\begin{array}{l}\text { Baylor Scott \& White McLane } \\
\text { Children's Medical Center, Texas, USA }\end{array}$ & $\begin{array}{l}\text { Only one parent allowed at a time with no restriction } \\
\text { on duration of visit }\end{array}$ & $\begin{array}{l}17 \text { March } 2020 \text { to September } 2020 \text { (to } \\
\text { date) }\end{array}$ \\
\hline
\end{tabular}

Our findings highlight the complex challenges of developing and implementing guidelines during a rapidly evolving novel pandemic, with limited evidence and experience available, and the expected tradeoffs on the established standard of care and its benefits. ${ }^{19}$ Some of the impacts may be mitigated by individualising policies to meet the unique requirements of the affected population and local centres, and in situations including end of life care or life-threatening surgeries/procedures, and by constant re-evaluation of emerging evidence and the impact of policies. ${ }^{19}$ Policy makers must recognise and reflect that parents are key partners in the care of their baby on the NICU and integral to optimal outcomes.

The free-text comments provided by parents highlighted the emotional and psychological burden of the restrictions on them. Preterm birth is associated with increased anxiety, post-natal depression (PND) and post-traumatic stress symptoms (PTSS) in both mothers

\begin{tabular}{|c|c|c|c|c|c|c|c|}
\hline & $\begin{array}{l}\text { NNUH } \\
\text { (25) }\end{array}$ & $\begin{array}{l}\text { ASPH } \\
\text { (27) }\end{array}$ & $\begin{array}{l}\text { SMH } \\
\text { (31) }\end{array}$ & $\begin{array}{l}\text { UHW } \\
\text { (10) }\end{array}$ & $\begin{array}{l}\text { SJHMC } \\
\text { (51) }\end{array}$ & $\begin{array}{l}\text { BSW } \\
(80)\end{array}$ & P value* \\
\hline Partner visiting less often & $13 / 23(57)$ & $14 / 26(53)$ & $11 / 31(35)$ & 2/9 (22) & $13 / 46(28)$ & $31 / 79(39)$ & 0.18 \\
\hline Not enough bonding & $17 / 23(74)$ & $12 / 23(52)$ & $6 / 25(24)$ & 2/8 (25) & $13 / 40(33)$ & 28/72 (39) & 0.02 \\
\hline Unable to participate in cares & $13 / 23(57)$ & 9/23 (39) & $3 / 25(12)$ & $1 / 8(13)$ & $6 / 40(15)$ & $19 / 72(26)$ & 0.01 \\
\hline Unable to receive updates & $7 / 23(30)$ & 8/23 (35) & $5 / 25(20)$ & $1 / 8(13)$ & $2 / 40(5)$ & 14/72 (19) & $0.08 \dagger$ \\
\hline Bring milk and supplies & $6 / 23(26)$ & $3 / 23(13)$ & $0(0)$ & $0(0)$ & $0(0)$ & $9 / 72(13)$ & $0.02 \dagger$ \\
\hline Breast feeding & & & & & & & $0.01 \ddagger$ \\
\hline No impact & $3 / 15(20)$ & $10 / 24(42)$ & $18 / 26(69)$ & $5 / 7(71)$ & 26/41 (63) & $34 / 58(59)$ & \\
\hline Mild impact & $6 / 15(40)$ & $7 / 24(29)$ & $7 / 26(27)$ & $2 / 7(29)$ & 14/41 (34) & $14 / 58(24)$ & \\
\hline Severe impact & $6 / 15(40)$ & $7 / 24(29)$ & $1 / 26(4)$ & $0(0)$ & 1/41 (3) & $10 / 58(17)$ & \\
\hline
\end{tabular}

Data are $n(\%)$.

*Analysed by chi-square test unless specified.

†Fisher's exact test.

$\ddagger$ Kruskal-Wallis test.

ASPH, Ashford and St Peter's Hospital; ; BSW, Baylor Scott \& White McLane Children's Medical Center; NNUH, Norfolk and Norwich

University Hospital; SJHMC, St Joseph's Hospital and Medical Center; SMH, St Michael's Hospital; UHW, University Hospital of Wales. 
and fathers; symptoms persist even at 2-4years postpartum. ${ }^{26-28}$ The additional impact of the COVID-19 pandemic and adding to their burden through restrictive visiting policies would seem only likely to increase the risk of PND and PTSS and disruption of parental-infant bonding. ${ }^{16} 19$

There are a few study limitations. While parents and public were not involved in the design and validation of the survey questionnaire, we included multiple options for free text and comments throughout and received many comments that described the significant impact of the visitation policies. This was designed as pragmatic survey whereby centres could participate any time during the study period once they received local approvals, hence different centres joined at different times with varying restriction policies. Respondents completed the survey at different times of their infants' hospitalisations, including a few at the time of admission, most during the hospitalisation and few after discharge. This may impact on their perceptions of visitation restrictions, but also allowed us to evaluate impact during different stages of hospitalisation. Each centre determined their own preferred method to distribute and collect responses, hence we are unable to provide a response rate as a proportion of the overall denominator population. Not all questions were answered by all respondents. Data included in the analysis had responses from at least $85 \%$ of respondents and we report denominators for response rate in each analysis. Our results may be affected by participation bias: those who responded may be more or less biased towards the restriction policy than the total parent population. Respondents, particularly first time parents, may have had difficulty in evaluating the impact of limitations if they had not experienced any other type of care; this was noted in a few comments. Our findings of significant association between severity of visitation policies and perceived impact may have been affected by confounding factors, such as variation in policies over time and differences between centres and countries. However, sample size was too small to perform secondary analysis to adjust for these factors. We attempted to account for multiple comparisons by using FDRs throughout the analyses.

Strengths of the study are the large number of responses obtained from six tertiary-level NICUs in two countries at a time when both were severely affected by the pandemic.

Comparing centres, the one with least restrictive policy reported a lower impact on breast feeding and bonding, whereas the centre with the most restrictive policy had the greatest adverse impact on breast feeding as reported by parents. These associations are important as they suggest a direct link between severity of restriction regime and impact on breast feeding.

We believe that our findings, showing that parents perceived a significant impact from visitation policies and an association of their impact with severity of restrictions are important as we enter a COVID-19 resurgence or 'second wave', and as centres consider/reconsider their visitation policies, hopefully with parents and babies foremost in mind

Author affiliations

${ }^{1}$ Department of Pediatrics, Creighton University School of Medicine, Omaha, Nebraska, USA

${ }^{2}$ Saint Joseph's Hospital and Medical Center, Phoenix, Arizona, USA

${ }^{3}$ Neonatology Association Limited, Obstetrix Medical Group of Phoenix, Mednax, Phoenix, United States

${ }^{4}$ Division of Neonatology, Department of Pediatrics, Baylor Scott and White McLane Children's Medical Center, Temple, Texas, USA

${ }^{5}$ Division of Neonatology, Department of Paediatrics, University Hospitals Bristol and Weston NHS Foundation Trust, Bristol, UK

${ }^{6}$ Neonatal Intensive Care Unit, Jenny Lind Children's Hospital, Norfolk and Norwich University Hospitals NHS Foundation Trust, Norwich, UK

${ }^{7}$ Neonatal Intensive Care Unit, Ashford and St Peter's Hospitals NHS Foundation Trust, Chertsey, UK

${ }^{8}$ Baylor Scott and White Research Institute, Temple, Texas, USA

${ }^{9}$ Neonatal Intensive Care Unit, University Hospital of Wales, Cardiff and Vale University Health Board, Cardiff, UK

${ }^{10}$ MEDNAX Inc, Sunrise, Florida, USA

${ }^{11}$ Norwich Medical School, University of East Anglia, Norwich, United Kingdom

Twitter Hemananda Muniraman @hmuniraman, Paul Cawley @PaulCawleyUK, Adam Heathcote @AdamHeathcote, Cora Doherty @NeolmprOutcomes and Paul Clarke @drpaulclarke

Acknowledgements We sincerely thank all parents who generously responded to our survey. We are most grateful to the reviewers for their valuable comments on the earlier version of our manuscript.

Contributors HM conceptualised and designed the study, designed the data collection instrument, obtained ethical/institutional research board approval, collected data, drafted the initial manuscript and revised the manuscript. MA, JH, AH, EG-C, SM, and ZC, recruited participants, collected data, reviewed and revised the manuscript. $\mathrm{KH}$ and $\mathrm{CR}$ designed and performed the data analysis, reviewed and revised the manuscript. VP, CD, AJ, VG and VR coordinated and supervised data collection and critically reviewed the manuscript for important intellectual content. PCawley coordinated and supervised data collection, revised and critically reviewed the manuscript for important intellectual content. PClarke co-designed the data collection instrument, coordinated and supervised data collection revised and critically reviewed the manuscript for important intellectual content. RC critically reviewed the manuscript for important intellectual content. All authors approved the final manuscript as submitted and agree to be accountable for all aspects of the work. HM is guarantor.

Funding The authors have not declared a specific grant for this research from any funding agency in the public, commercial or not-for-profit sectors.

Competing interests None declared.

Patient consent for publication Not required.

Ethics approval The study was determined exempt from requiring full review by the institutional review board at St Joseph's Hospital and Medical Center (PHXNR-20-500-170-73-21) and was approved by MEDNAX Research Advisory Committee (RA ID: 607025162). All participating centres obtained approval from their respective research governance managers and/or ethics/institutional boards prior to commencing the study.

Provenance and peer review Not commissioned; externally peer reviewed.

Data availability statement Data are available upon reasonable request. Deidentified participant data are available upon request.

Supplemental material This content has been supplied by the author(s). It has not been vetted by BMJ Publishing Group Limited (BMJ) and may not have been peer-reviewed. Any opinions or recommendations discussed are solely those of the author(s) and are not endorsed by BMJ. BMJ disclaims all liability and responsibility arising from any reliance placed on the content. Where the content includes any translated material, BMJ does not warrant the accuracy and reliability of the translations (including but not limited to local regulations, clinical guidelines, terminology, drug names and drug dosages), and is not responsible for any error and/or omissions arising from translation and adaptation or otherwise. 
Open access This is an open access article distributed in accordance with the Creative Commons Attribution Non Commercial (CC BY-NC 4.0) license, which permits others to distribute, remix, adapt, build upon this work non-commercially, and license their derivative works on different terms, provided the original work is properly cited, appropriate credit is given, any changes made indicated, and the use is non-commercial. See: http://creativecommons.org/licenses/by-nc/4.0/.

ORCID iDs

Hemananda Muniraman http://orcid.org/0000-0003-0254-2607

Paul Cawley http://orcid.org/0000-0002-4353-0656

Paul Clarke http://orcid.org/0000-0001-6203-7632

\section{REFERENCES}

1 Griffin T. A family-centered "visitation" policy in the neonatal intensive care unit that welcomes parents as partners. J Perinat Neonatal Nurs 2013;27:160-5.

2 Davidson JE, Aslakson RA, Long AC, et al. Guidelines for familycentered care in the neonatal, pediatric, and adult ICU. Crit Care Med 2017;45:103-28.

3 Als H, McAnulty GB. The newborn individualized developmental care and assessment program (NIDCAP) with kangaroo mother care (KMC): comprehensive care for preterm infants. Curr Womens Health Rev 2011;7:288-301.

4 O'Brien K, Bracht M, Macdonell K, et al. A pilot cohort analytic study of family integrated care in a Canadian neonatal intensive care unit. BMC Pregnancy Childbirth 2013;13 Suppl 1:S12.

5 Lee SK, O'Brien K, O'Brien K. Parents as primary caregivers in the neonatal intensive care unit. CMAJ 2014;186:845-7.

6 Patel N, Ballantyne A, Bowker G, et al. Family integrated care: changing the culture in the neonatal unit. Arch Dis Child 2018;103:415-9.

7 O'Brien K, Robson K, Bracht M, et al. Effectiveness of family integrated care in neonatal intensive care units on infant and parent outcomes: a multicentre, multinational, cluster-randomised controlled trial. Lancet Child Adolesc Health 2018;2:245-54.

8 Conde-Agudelo A, Díaz-Rossello JL. Kangaroo mother care to reduce morbidity and mortality in low birthweight infants. Cochrane Database Syst Rev 2016:CD002771.

9 Welch MG, Firestein MR, Austin J, et al. Family nurture intervention in the neonatal intensive care unit improves social-relatedness, attention, and neurodevelopment of preterm infants at 18 months in a randomized controlled trial. J Child Psychol Psychiatry 2015;56:1202-11.

10 WHO coronavirus disease (COVID-19) Dashboard. Available: https:// covid19.who.int/ [Accessed 20 Oct 2020].

11 Zhang Z-J, Yu X-J, Fu T, et al. Novel coronavirus infection in newborn babies aged $<28$ days in China. Eur Respir $J$ 2020;55:2000697.

12 Ma X, Zhu J, Du L. Neonatal management during the coronavirus disease (COVID-19) outbreak: the Chinese experience. Neoreviews 2020;21:e293-7.
13 Sheth S, Shah N, Bhandari V. Outcomes in COVID-19 positive neonates and possibility of viral vertical transmission: a narrative review. Am J Perinatol 2020;37:1208-16.

14 Knight M, Bunch K, Vousden N, et al. Characteristics and outcomes of pregnant women admitted to hospital with confirmed SARSCoV-2 infection in UK: national population based cohort study. BMJ 2020;369:m2107.

15 National Perinatal COVID-19 (NPC-19) Registry Update. Available: https://my.visme.co/view/ojq9qq8e-npc-19-registry [Accessed 20 Oct 2020].

16 Erdei C, Liu CH. The downstream effects of COVID-19: a call for supporting family wellbeing in the NICU. J Perinatol 2020;40:1283-5.

17 Darcy Mahoney A, White RD, Velasquez A, et al. Impact of restrictions on parental presence in neonatal intensive care units related to coronavirus disease 2019. J Perinatol 2020;40:36-46.

18 Benjamini Y, Hochberg Y. Controlling the false discovery rate: a practical and powerful approach to multiple testing. J $R$ Stat Soc Ser B 1995;57:289-300.

19 Virani AK, Puls HT, Mitsos R, et al. Benefits and risks of visitor restrictions for hospitalized children during the COVID pandemic. Pediatrics 2020;146:e2020000786.

20 Initial guidance: management of infants born to mothers with COVID-19. Available: https://www.aappublications.org/news/2020/ 04/02/infantcovidguidance040220 [Accessed 09 Jan 2020].

21 Management of infants born to mothers with suspected or confirmed COVID-19. Available: https://www.aappublications.org/ news/2020/07/22/newbornguidance072220 [Accessed 09 Jan 2020].

22 Royal College of Obstetricians \& Gynaecologists. Coronavirus (COVID-19) infection in pregnancy: information for healthcare professionals, 2020.

23 COVID-19 - guidance for neonatal settings. Royal College of Paediatrics \& Child Health, 2020. Available: https://www.rcpch.ac. uk/resources/covid-19-guidance-neonatal-settings\#parents-andvisitors-to-nnu [Accessed 17 Sep 2020].

24 Frequently Asked Questions within Neonatal Services. A BAPM supplement to RCPCH guidance, 2020. Available: https://hubblelive-assets.s3.amazonaws.com/bapm/redactor2_assets/files/561/ COVID-FAQs 5.7.20.docx.pdf [Accessed 17 Sep 2020].

25 Bliss. Bliss statement: COVID-19 and parental involvement on neonatal units, 2020

26 Åhlund S, Clarke P, Hill J, et al. Post-traumatic stress symptoms in mothers of very low birth weight infants 2-3 years post-partum. Arch Womens Ment Health 2009;12:261-4.

27 Alexander AL, Clarke P, Rushworth I, et al. PTSS in fathers of VLBW infants two to four years postpartum: a pilot study. Clin Pract Pediatr Psychol 2020;8:25-36.

28 Shaw RJ, Sweester CJ, St John N, et al. Prevention of postpartum traumatic stress in mothers with preterm infants: manual development and evaluation. Issues Ment Health Nurs 2013;34:578-86. 